\title{
A BANALIDADE DO EXIBICIONISMO E A CONSTRUÇÃO DE UMA CULTURA DO ÓDIO NA SOCIEDADE DIGITAL
}

\section{THE BANALITY OF EXHIBITIONISM AND THE BUILDING A CULTURE OF HATE IN DIGITAL SOCIETY}

\author{
${ }^{1}$ Marcos Antonio Madeira De Mattos Martins
}

\section{RESUMO}

A sociedade digital trouxe ao homem tecnologias repletas de conectividades e funções, criando agilidade para troca de informações. Com a possibilidade de compartilhar sua vida privada na rede social, o culto ao eu passou a ser utilizado como forma de banalização do exibicionismo. Dos conflitos virtuais, criou-se uma aldeia de usuários que discriminam pessoas pela cor, raça, etnia, religião e manifestação de pensamentos, emergindo uma cultura do ódio, da intolerância. Os valores morais da sociedade digital estão enfraquecidos pelo hábito de compartilhamento de uma linguagem que demonstra a tendência do desrespeito ao princípio da dignidade humana.

Palavras-chave: Sociedade informacional, Tecnologia, Dignidade humana

\begin{abstract}
The digital society brought the man full of technology and connectivity functions, creating agility to exchange information. With the ability to share your privacy in the social network, the selfie culture began to be used as a form of trivialization of exhibitionism.Virtual conflicts was created a community of users that discriminate people by color, race, ethnicity, religion and expression of thoughts, crerating a culture of hatred, intolerance. The moral values of the digital society are weakened by sharing habit of language that shows the trend of disregard for the principle of human dignity.
\end{abstract}

Keywords: Information society, Technology, Human dignity

\footnotetext{
${ }^{1}$ Doutor em Direito pela Pontifícia Universidade Católica de São Paulo - PUC, São Paulo,( Brasil). Professor de Mestrado em Administração e Governança Corporativa das Faculdades Metropolitanas Unidas - FMU - São Paulo. E-mail: marcosmartinsadv@gmail.com
} 


\section{INTRODUÇÃO}

O aprimoramento dos microcomputadores e a sofisticação de telefones celulares multifuncionais introduziram o ser humano em redes de comunicação digitalizadas, alterando as relações sociais. Os contatos físicos começaram a ser substituídos pela conferência virtual. A tecnologia da informação proporcionou a propagação de funcionalidades de comunicação, criando a cooperação integrada de seus usuários, reduzindo os espaços entre os agentes econômicos, viabilizando o encontro virtual entre pessoas e famílias, que cada vez mais buscam aplicativos inovadores concentrados em tecnologias cada vez mais sofisticadas.

A linguagem representada por mensagens de fácil compreensão entre os usuários foi sendo migrada aos aparelhos multifuncionais (smartphones), transformando a forma de expressão em conversas corriqueiras pela minimização dos sinais, dos códigos e dos signos representativos. Reduziu-se a construção de uma linguagem completa nos relacionamentos para sinais minimizados de imagens ou ícones expressionistas.

Essa alteração de expressão de linguagem em diversas plataformas de comunicação provocou, paulatinamente, a substituição da própria mensagem escrita por fotografias, por imagens representativas para chamar a atenção dos usuários de forma instantânea.

A exposição da privacidade de pessoas passou a fazer parte integrante de uma rotina diária de todos os usuários de redes sociais. O que poderia ser somente um modismo passou a integrar o cotidiano das pessoas, que passaram a se fotografar sozinhas ou com amigos, a filmar cenas do cotidiano através de smartphones, compartilhando com diversos grupos para reconhecimento dos usuários interligados à rede digital.

O público e o privado se confundem quando usuários expandem a usabilidade desses smartphones, compartilhando mensagens ou vídeos de forma generalizada. A banalidade do exibicionismo dos usuários, como meio de exposição da vida privada individual do homem, parece ter se perdido na utilidade, no objetivo da mensagem e na linguagem, revelando-se desmedida e estéril a cultura da postagem de imagem sem utilidade pública.

As normas que buscam proteger aos valores mais íntimos dos seres humanos são confrontadas com princípios do direito da liberdade de expressão, fragilizando-se em meio à eclosão de fatos, gravações, imagens e conteúdos que são postados em rede, pouco importando o resultado lesivo que tais condutas possam gerar a terceiros.

Se não bastassem as lesões aos valores personalíssimos deflagradas por pessoas comuns que se passam por cinegrafistas do cotiando, o usuário também descobriu que pode 
partilhar sua intimidade com pessoas próximas ou desconhecidas, desde uma simples imagem do local está situado, até imagens de partes íntimas de seu corpo.

O culto ao eu ${ }^{1}$ deu ensejo a uma avalanche de imagens de pessoas que participam de redes sociais e que vive no afã de mostrar, em diversos aplicativos dos smartphones ou computadores interligados, o que elas estão fazendo num determinado momento; com quem elas estão convivendo; porque elas estão em certo local; o que estão consumindo; o que estão curtindo; quais as pessoas que participaram do evento; enfim, exibem suas imagens como sendo fonte única e indispensável de prazeres que conseguem proporcionar socialmente.

Ao mesmo tempo em que algumas pessoas exercitam diariamente o culto ao eu, outras pessoas, também usuárias da rede digital, acabam repudiando essas ações ou não concordando com esse modo egocentrista de divulgação, rebatendo, muitas vezes de forma hostilizada, as cenas ou as mensagens postadas na rede. Emergiu, desse confronto de ideias, uma cultura paralela, intimamente ligada ao ódio, centrada no fato da discordância direta da ostentação pessoal.

A intolerância surgiu nas redes digitais, trazendo a discriminação social, a imposição de um preconceito de origem, raça, cor, idade, crença, entre outros descompassos.

O paradoxo é contínuo: enquanto um grupo de pessoas banalizam seus valores morais publicando suas intimidades em redes sociais, por uma concorrência exibicionista de cultivar o egocentrismo, outras pessoas, totalmente adversas, cultuam o ódio, demonstrandose intolerantes com diversos tipos de postagens, perseguindo usuários, denegrindo imagens, maculando a honra e a própria ação dos exibicionistas na rede.

O presente artigo visa discutir o culto ao exibicionismo e a cultura do ódio que se expande nas redes sociais, subtraindo valores com minimização de linguagens que mitigam o desenvolvimento humano e retiram o fim da utilidade pública das redes sociais, que deveria estar focada na integração e no compartilhamento de informações úteis para possibilitar a difusão da reflexão e do conhecimento.

A pesquisa visa elucidar o embate entre a ostentação de pessoas nas redes sociais e a edificação da intolerância que exibem o prazer em ofender outros usuários, desvirtuando a essência dos canais digitais que foram criados para cooperação mútua entre os povos e distribuição de informação de forma fraterna.

\footnotetext{
${ }^{1}$ Expressão que visa demonstrar uma conotação próxima com “self”, ou seja, guarda correspondência com o que é próprio do ser humano e se alimenta do universo para se tornar único e desejável, em sua essência (estrutura) e existência (processo), em todos os canais de interlocução.
} 


\section{O HOMEM NA REDE VIRTUAL E O SURGIMENTO DA CIBERCULTURA}

Os ambientes de rede de informação, notadamente, aqueles disponibilizados pela Internet, eram cultivados por empresas de tecnologia avançada a fim de auxiliar os consumidores a buscar alternativas diferentes de produtos, opinar por bens e serviços disponibilizados em redes de empresas, estimularem a divulgação de nomes, de marcas, de logomarcas no mercado virtual, introduzindo programas capazes de atingir todos os níveis sociais da economia.

Com a expansão econômica fundada em novas tecnologias, o homem passou a utilizar o canal de comunicação como instrumento de trabalho, entretenimento e aperfeiçoamento de seus conhecimentos.

Thomas L. Friedman lembra que a propagação de computadores pessoais, aparelhos de fax, programas como Windows e modems conectados a uma rede de telefone global se juntou "no fim dos anos 1980 e início dos anos 1990 para criar a plataforma básica que deu início à revolução global da informação." 2

O esforço comum, naquela ocasião, era o de combinar todos os aparelhos de comunicação e os programas e sistemas de rede, transformando-os em um único sistema operacional, capaz de atender todos os anseios de seus usuários.

Através de uma plataforma de comunicação global, esse sistema operacional passou a ser traduzido para quase todos os idiomas, atingindo todos os países e continentes que estivessem conectados à rede social digital. ${ }^{3}$

A Internet nasceu como um instrumento virtual de comunicação. O homem, então, começou a migrar para as janelas da virtualização, levando consigo sua profissão, sua família e seus ensejos, transferindo aos aplicativos portáteis novas ferramentas digitais para uso e prospecção de seu desenvolvimento.

O conhecimento e o processamento de informações foram substancialmente alterados pelas novas tecnologias. A organização da sociedade está pautada na necessidade de geração, processamento e transmissão de informação, como fontes de produtividade e poder. ${ }^{4}$

\footnotetext{
${ }^{2}$ FRIEDMAN, THOMAS L. O mundo é plano. Rio de Janeiro: Ed. Objetiva, 2007, p. 73.

${ }^{3}$ Ibid, pp. $72-73$

${ }^{4}$ CASTELLS, Manuel. A sociedade em rede. A Era da Informação: economia, sociedade e cultura. Volume I, 5 ed., São Paulo: Paz e Terra, 2001, p. 33-34.
} 
O usuário começou a testar a via digital não somente para expandir seu conhecimento profissional ou fazer negócios, mas também para fazer parte de comunidades virtuais, verdadeiras aldeias digitais, onde ele passou a ser protagonista de eventos, difusor de informações, cinegrafistas de imagens flagradas no cotidiano, justamente por estar conectado num mundo cujas postagens produzem efeito viral.

Essa nova forma de agir do usuário, reprodutor de cenas, criou uma nova economia digital e alterou, sobremaneira, a cultura do marketing. Nessa economia digital, o homem ingressou na virtualização de um mundo pessoal e particular, que, ao ser analisada de forma profunda, tenta elevar um grau de importância para outras pessoas, pois, para o homem digital, o virtual é a extensão de sua vida real.

Para Pierre Lévy, "a "virtualização pode ser definida como o movimento inverso da atualização." Para o autor, tal expressão consiste em uma "passagem do atual ao virtual", na “elevação à potência da entidade considerada". A "virtualização não é uma desrealização (a transformação de uma realidade num conjunto de possíveis), mas uma mutação de identidade, um deslocamento do centro de gravidade ontológico do objeto considerado". 5

O homem digital tem obrigação de saber lidar com telefones celulares inteligentes (smartphones), pois a mutação da identidade física para a digital cria a perspectiva de uma linguagem mais ampla, com a inclusão da figura e perspectiva da manifestação do outro, que também está presente naquele canal de comunicação.

Essa forma de lidar com a linguagem e sua repercussão ${ }^{6}$ alimenta novos meios de interlocução entre os diversos usuários nos meios social, econômico e também organizacional. A mudança de comportamento nas relações humanas trouxe um antagonismo corriqueiro do homem no meio social em que ele vive e reproduz seus pensamentos e imagens, passando a viver entre o real e o surreal. O real pode ser concebido como aquilo que ele tem ciência que é finito e que pode ser alcançado, e, portanto, sente-se impotente para realização de certos eventos e tem noção de seus limites; o surreal, atrelado à rede digital, está ligado ao infinito, transgride a verdade sensível e torna absurda a potência de expansão do conhecimento.

O homem digital passa a questionar o que é verdade, quais são as informações que ele deve se preocupar e até que ponto uma mensagem pode ser considerada interessante para

\footnotetext{
${ }^{5}$ LÉVY, Pierre. O que é virtual? Tradução Paulo Neves. São Paulo: Ed. 34, 2009, p. 17

${ }^{6} \mathrm{O}$ ser humano é capaz, por ser sujeito psicológico, sujeito da razão e do logos, de expressar uma dupla função da linguagem: a de "representar" o pensamento que, ele mesmo, por sua vez, representa o mundo, e ainda, o de "comunicar" ou "expressar" a outras pessoas suas representações. Saussure também distingue a "língua e seus uso social, variável e múltiplo (o discurso, a fala, a comunicação)" para os fins que a mente humana deseja expressar em certas circunstâncias. SAUSSURE, Ferdinand de. Curso de Linguísta Geral. Org. Charles Bally e Albert Sechebaye. Trad. Antonio Chelini. São Paulo, Cultrix, 2006, pp. 15-44.
} 
compartilhamento. A liberdade de expressão encerra no próprio ser humano o questionamento do que deve ser publicizado, do que é falso e do que é verdadeiro.

Hegel expôs essa preocupação entre correlação entre o ser humano e a verdade. Para o filósofo, a separação entre o "ser em si e o ser para si no finito" se constitui, simultaneamente, "a sua existência bruta e a aparência". O "intelecto considera esta determinação como absoluta e definitiva", encerra-a na relação a "uma matéria dada que não pertenceria à essência da mesma liberdade. Assim se limita o intelecto ao que há de abstrato na liberdade sem alcançar a sua ideia e a sua verdade." 7

Essa liberdade cultivada entre o eu e os outros passa a tomar outra proporção quando ela, ao mesmo tempo, colide e se harmoniza com outros posicionamentos que são partilhados em um mesmo campo de discussão. A multidão de opiniões e de fragmentos de mensagens publicados por diversos usuários que participam de um mesmo universo digital acabam abalando o movimento do ser e do agir humano no universo real.

A evolução desse movimento digital, denominado cibercultura ${ }^{8}$ por Pierre Lévy, criou novos espaços sociais e colocou o homem num oceano de informações, imagens, figuras, signos que ele não tinha vivenciado até o surgimento da sociedade virtual.

Pierre Lévy adverte os usuários sobre o impacto das tecnologias sobre a construção da inteligência coletiva, utilizando para as contradições que podem surgir no meio, denominado pelo autor como "veneno e remédio da cibercultura". Em sua narrativa, o autor sinaliza que a sociedade "encontra-se condicionada, mas não determinada pela técnica", permitindo uma interpretação biunívoca entre sociedade e tecnologia, mediante a qual a primeira se constitui historicamente pela segunda, embora não seja por ela determinada. ${ }^{9}$

Sob o aspecto sociológico, as novas tecnologias provocaram ao homem uma sensação de liberdade sem fixar limites do que deve ser divulgado. $O$ virtual permitiu ao homem maior espaço de penetração no mundo e com ele veio uma expansão de toda infinitude de sentimentos e pensamentos impingidos em rede digital.

Esse espaço de interlocução entre os usuários possui dimensão ilimitada, integrando, todos os usuários, a uma democracia informática direta e participativa em tempo real, onde a

\footnotetext{
${ }^{7}$ HEGEL, Georg Wilhelm Friedrich. Princípios da filosofia do direito. Tradução: Orlando Vitorino. São Paulo: Martins Fontes, 2009, p. 19.

8 “O termo [ciberespaço] especifica não apenas a infraestrutura material da comunicação digital, mas também o universo oceânico de informação que ela abriga, assim como os seres humanos que navegam e alimentam esse universo. Quanto ao neologismo 'cibercultura', especifica aqui o conjunto de técnicas (materiais e intelectuais), de práticas, de atitudes, de modos de pensamento e de valores que se desenvolvem juntamente com o crescimento do ciberespaço". LÉVY, Pierre. Cibercultura. Trad. Carlos Irineu da Costa. São Paulo: Editora 34, 2009, p. 17.

${ }^{9}$ Ibidem.
} 
instantaneidade passa a ser a válvula propulsora das ações humanas e o racional passa a ficar em segundo plano.

\section{PADRÕES DE INDIVIDUALISMO E EXIBICIONISMO NA INTERNET E A AUSÊNCIA DE LIMITES}

O homem digital é sujeito ativo de informações em uma rede de consumo. Com a possibilidade de exibir sua vida privada e seus pensamentos na rede social, o homem passou a ser objeto de consumo, transformando-se em mercadoria. Por ser produtor e consumidor de informações, percebeu o usuário da rede que ele poderia criar seu próprio mundo virtual porque não existe regulação imediata sobre seus valores pessoais jogados no ciberespaço.

Bauman ensina que o ambiente existencial e a oferta de informações sobre produtos, criou uma "sociedade de consumidores" que se distingue por uma "reconstrução das relações humanas a partir do padrão, e à semelhança, das relações entre os consumidores e os objetos de consumo." Pontua, ainda, o autor, que numa "sociedade de consumidores, ninguém pode se tornar sujeito sem primeiro virar mercadoria". A "subjetividade" do sujeito e a "maior parte daquilo que essa possibilita ao sujeito atingir, concentra-se num esforço sem fim para ela própria se tornar, e permanecer, uma mercadoria vendável". ${ }^{10}$

O consumidor de informação tira proveito de "benefícios" antes não presentes em sua rotina, como "ubiquidade, instantaneidade, interatividade, acessibilidade, conexão imediata", permitindo a ele a participar ativamente de diversos grupos em redes sociais. ${ }^{11}$

No marketing da intimidade, o sucesso está nos produtores que conseguem efetiva e eficientemente envolver o consumidor individual no processo de criar e entregar o exato produto ou serviço desejado. O objetivo é desenvolver uma situação na qual a venda é o ápice de um longo processo de integração do consumidor em estágios significativos da atividade comercial. Os conceitos de massa, segmentos e grupos de consumidores deram lugar, em última análise, à ideia de que a massa constitui-se de um único indivíduo como segmento.

A estratégia dos grandes empresários fundou-se na compreensão das expectativas do consumidor individual e o esforço para não apenas satisfazê-las, mas excedê-las. Nos mercados industriais e comerciais, criar uma familiaridade como o consumidor pode demandar o envolvimento de todo o sistema de fornecimento e valor, essencialmente integrado e organizado em função das necessidades dos usuários finais. Essa integração já

\footnotetext{
${ }^{10}$ BAUMAN, Zygmunt. Vida para consumo: a transformação das pessoas em mercadoria. Rio de Janeiro. Zahar, 2008, pp 16-20.

${ }^{11}$ MATOS, Karla Cristina da Costa e Silva. O valor econômico da informação nas relações de consumo. São Paulo: Almedina, 2012, p. 91.
} 
está acontecendo em várias indústrias - varejo, automóveis, bancos, eletrônica e sistemas de saúde, para citar algumas, e muitas outras já estão sentindo a pressão dos consumidores ou das economias globais. $^{12}$

Ao clicar em uma foto e expor a imagem na Internet, seja num blog, no Facebook ou qualquer meio digital de comunicação, o ser humano começa a mostrar sua identidade, transformando-se em uma pequena sociedade ${ }^{13}$. Essa pequena sociedade está repleta de sentimentos, desejos, angústias e cobranças armazenadas em sua mente e que se torna concreta e purificador da alma ao ser contemplado.

$\mathrm{Na}$ contemplação do ser digital (no sentido de existir e ser reconhecido) ocorre uma realização pessoal da individualidade, do ser único, no instante em que outros usuários podem curtir e compartilhar seus pensamentos, seus sonhos, seus ideais, suas dores, suas angústias. O ser digital tornar-se uma pessoa biunívoca, transformando-se em individual e múltipla, capaz de estar presente na vida real e no virtual.

Com certa frequência, não se espera do homem digital uma causa para agir, pois seus valores morais ${ }^{14}$ cindidos e desvirtuados pelo excesso das informações, pelo excesso de cobrança que é feita pela própria sociedade virtual para estimular sua participação em redes sociais com a finalidade de sentir-se incluído socialmente, ainda que o costume de postagem de informações e imagens não tenha ou ofereça qualquer utilidade para seus pares.

David Hume argumenta que o homem deveria ser movido por uma "causa" e, essa "causa" deveria gerar efeitos sobre o meio social. Existe uma relação entre "causa" e "efeito" que conduzem o homem à interação mútua. Desde a reflexão sobre algo até a exteriorização de seu pensamento sobre determinado fato, o homem "produz" algo por força de uma causa antecedente. ${ }^{15}$ Entretanto, ao contrário do que ensina Hume, o homem digital não busca uma causa em si para mover-se em direção a um fim no mundo virtual. Parece que, dentro de uma

\footnotetext{
12 OLIVER, Richard W. Como serão as coisas no futuro. Tradução Nathalie Fragoso. São Paulo. Negócio Editora, 1999, pp. 94-95.

${ }^{13}$ NOVALIS, F. von Hardenberg. Pólen. Trad. Rubens Rodrigues Torres Filho, São Paulo, 1988, p. 7.

${ }^{14}$ Os valores morais estariam ligados ao dever-ser de uma sociedade que busca o bem comum. Para reformar esse novo projeto de "humanidade", haveria a necessidade de duas vias: a "via interior, a das mentes e das almas, a das éticas, das caridades e das compaixões" e ainda da "via exterior", para "mudança das instituições e das estruturas sociais." MORIN, Edgar. Rumo ao abismo? Ensaio sobre o destino da humanidade. Trad. Edgard de Assis Carvalho, Mariza Perassi Bosco. Rio de Janeiro: Bertrand Brasil, 2011, p. 90.

${ }^{15}$ No entendimento de David Hume, não que toda produção de algo pressupõe causa anterior. "Um objeto pode ser contíguo e anterior a outro, sem ser considerada sua causa." No entanto, Hume entende que existem "relações" entre uma "produção" e uma "causa". Ou seja, para que existe algo, há a causalidade geradora para justificar essa produção. Para Hume, "Trata-se de uma máxima geral da filosofia que tudo que começa a existir deve ter uma causa para sua existência." HUME, David. Tratado da natureza humana: uma tentativa de introduzir o método experimental de raciocínio nos assuntos morais, pp. 105-107.
} 
perspectiva crescente, o objetivo do homem digital nas redes é, apenas, ser produto do reconhecimento e do compartilhamento de sua linguagem e imagem.

O homem da era digital espera que essa causa de agir seja seu próprio existir e, por consequência, entende que também deve ser celebridade. $\mathrm{O}$ antropocentrismo ${ }^{16}$ projetado no ciberespaço começa a dar sinais de ressurgimento após séculos de passagem, pois à medida que a causa e efeito não é mais questionada em sociedade pela expansão de imagens do eu, provoca-se, a partir dessa concepção, o cultivo do compartilhamento das imagens humanas como forma de produto e meio de resgate da felicidade do homem.

Giannetti alerta para as mudanças de padrão do homem na era da Internet e a massificação das ofertas para consumo: para o homem a "realidade objetiva não é toda realidade - é apenas parte dela." Ocorre que "se você ficar só com ela, uma vez que ela apenas se presta a ser publicamente observada, testada e medida de fora, então você estará deixando de lado toda a realidade subjetiva". E a realidade subjetiva, ou seja, os sentimentos, "é o nosso mundo interno, a nossa experiência pessoal e avassaladora de sermos quem somos, isto é, de não sermos simples máquinas calculadoras ou pedaços de química tresloucada." 17

O exibicionismo do ser humano na Internet e nas redes sociais demonstra a necessidade intensa dos usuários em se sentirem diferentes dentre os iguais, úteis e singulares, ainda que tais exibições de sentimentos sejam falsas. O que importa, no final, é sentir-se valorizado por seus pares, devido à massificação física e perda da identidade social.

A busca do sentimento de felicidade que se espraia pelos usuários que compartilham fotos, vídeos e imagens, é medida através da aclamação do público que assiste cenas e imagens refletidas em monitores de computador ou telas de smartphones.

A utilização de tecnologias de alta performance possibilita a exibição daquilo que está em volta do ser humano. A "redução à linguagem binária dos bits (unidades mínimas de informação) dos diferentes conteúdos", podendo ser "visuais ou sonoros", anuncia uma intensa "eclosão do mercado, um acúmulo de oferta informativa, de ócio e entretenimento como jamais experimentaram as sociedades desenvolvidas." 18

O exibicionismo do homem digital revela a cumplicidade de desejos manifestados entre o bem e o mal. Sentimentos são jorrados pelo ser humano num aparelho multimídia

\footnotetext{
${ }_{16}$ Antropocentrismo traz a concepção do ser humano como figura principal na sociedade. É uma concepção histórica, que foi fundada a partir da ruptura das estruturas do poder entre a igreja (teocentrismo) e o monarca, surgindo através do movimento humanista renascentista entre o século XV e XVI, na Europa. In CICCO, Cláudio de. História do pensamento jurídico e da filosofia do direito. 3 ed. São Paulo: Saraiva, 2006, p. 68.

${ }^{17}$ GIANNETTI, Eduardo. Felicidade: diálogos sobre o bem-estar na civilização. São Paulo: Companhia das Letras, 2002, p.32.

${ }^{18}$ CEBRIÁN, Juan Luis. A rede. Tradução Lauro Machado Coelho. São Paulo: Summus, 1999, p. 36.
} 
conectado com o mundo e as postagens não têm limites, pois o que remetente busca da rede são aceitações e compartilhamentos de suas imagens (gestos ou palavras) ou de seus pensamentos como forma de reiterada conexão com a integração social.

Pouco importa o limite do exibicionismo, tampouco se tais postagens possam gerar danos a seus pares. O que importa, na banalidade do exibicionismo, é o protagonismo das cenas comuns e frívolas, dos boatos imediatos trocados com usuários e da alta recepção de sinais e demonstração do poder de sua conectividade.

\section{DO NARCISISMO AOS BRAGGERS: A INVASÃO E DIFUSÃO DAS TECNOLOGIAS SELF}

É fato que o "armazenamento em memória digital é uma potencialização" e a "exibição é uma realização." ${ }^{19}$ O computador passa a ser um instrumento mais eficiente que uma máquina de escrever mecânica, embora um texto digitado por ambos tenham igual valor, porém o computador permite ao leitor "divulgar automaticamente interagindo com um computador a partir de uma matriz digital, penetramos num novo universo de criação e leitura dos signos." 20

A digitalização da vida humana - ou seja, a inserção da imagem do homem numa rotina armazenada em dados - acabou trazendo novos modelos de comportamento que são questionáveis pelos demais usuários.

Costumes começam a ser incorporados na rotina da vida do homem e o que era tido como ostentação, passa a ser comum numa sociedade que tem mitigado seus valores morais. O homem tira foto de si mesmo e posta nas redes sociais. Ele idolatra a si mesmo e espera reconhecimento ou aceitação de seus pares.

O narcisismo impera na sociedade da informação como forma de integração do corpo e da alma dos usuários em diversas dimensões e proporções, criando e reforçando a importância do eu perante a coletividade. ${ }^{21}$

A presença da propagação do narcisismo na sociedade é latente quando se vislumbra o crescente número de aparelhos de telefone celular que já suportam câmeras de fotos e vídeo na parte frontal; aparelhos de gravação de vídeo fabricados em todos os tipos de tamanho e

\footnotetext{
${ }^{19}$ LÉVY, Pierre. O que é virtual? Op. cit. pp. 17-18.

${ }^{20}$ Ibid, p. 41.

${ }^{21}$ Para Freud, o narcisismo é compreendido como o estágio no qual as "pulsões parciais, até então isoladas, reuniram-se numa unidade e simultaneamente acharam o ego como objeto". Para psicanálise, representa um modo particular de relação com a sexualidade. O narcisismo é um protetor do psiquismo e um integrador da imagem corporal. Esse modo de expressão tem como fim a integração do corpo em diversas dimensões, proporções e a possibilidade de uma identidade, de um eu. FREUD, S. Introdução ao narcisismo. in Obras Completas. Buenos Aires: Amorrortu Editores, vol. 14. pp. 66-72.
} 
ótima qualidade de captação de imagens; câmeras escondidas de alta tecnologia para flagrar a intimidade das pessoas, enfim, aparatos sofisticados que mostram e exibem o ambiente íntimo e privado para o público.

A expressão self - aqui utilizada como conexão do culto ao eu - encontra seu nascedouro na própria fase do reconhecimento humano.

Ricouer sustenta que o reconhecimento tem origem em "verbo dotado de voz ativa e voz passiva", ou seja, "reconhecer e ser reconhecido." Reconhecer é um ato que busca a compreensão do ser. Para que o "reconhecimento possa criar identidade recíproca", mormente no plano político, “torna-se necessário se estabelecer uma relação dialética entre as partes, isto é, um reconhecimento mútuo." 22

O reconhecimento importa na inclusão do outro no mundo em que se vive. O que determina a alteridade é o reconhecimento de que o eu reconhece o outro e o outro reconhece o eu de forma recíproca. Essa reciprocidade guia a "ação como se eu fosse o outro, como seu eu estivesse em seu lugar, pensando a partir da sua noção de bem.” 23

A alteridade, então, por partir da concepção irrenunciável de que somente com o outro o eu pode se reconhecer e ser reconhecido impele um elo de comunicação entre os seres humanos para, em busca contínua das satisfações das necessidades mútuas, estabelecer uma solidez, uma concretude nas relações.

Em decorrência da necessidade de se encontrar o reconhecimento, os aplicativos das redes sociais e da própria Internet são tendenciosos a cada vez mais mostrar o eu para o outro.

Além de celulares e câmeras de vídeos, plataformas de exibição de filmes amadores, fotos tiradas por meio de self com partes seminuas do corpo ou totalmente nuas, fazem parte de acervo de novas linguagens de comunicação.

Iniciou-se uma onda de postagens feitas pelos denominados braggers (expressão originada da língua inglesa, representam pessoas que se "gabam", que demonstram extrema "vaidade"). ${ }^{24}$ Motivo de diversas discussões, a Universidade de Humboldt, Berlim, entrevistaram 357 universitários que se relacionam com braggers e descobriram que o principal sentimento despertado pela vida virtual é a inveja. Quase 30\% relataram nutrir esse sentimento ao ver, no Facebook, posts sobre atividades de lazer dos amigos e indícios de

${ }^{22}$ Paul Ricouer observa, inda, que "Reconhecer é um ato unilateral que exprime a pretensão de exercer uma superioridade intelectual no campo das asserções significativas em relação a quem deve ser reconhecido.”. Daí a necessidade do outro para questionamento e reflexões dos atos do eu. Sem a identificação do outro, a ação humana ficaria sem direcionamento, sem objetivos adequados para um fim comum. RICOUER, Paul. Parcous de la reconnaissance. Paris: Gallimar, 2003, pp. 39-40

${ }^{23}$ Ibid., pp. 367-369.

24 Michaelis on line. Disponível em http://michaelis.uol.com.br/moderno/ingles/index.php?lingua=ingles- 
sucesso de qualquer espécie (acadêmico, profissional, sexual). Mesmo os exibidos sentem inveja. Cerca de $20 \%$ afirmaram chatear-se por sentir que sua própria ostentação não é notada suficientemente pelos amigos. $^{25}$

A gravação de vídeos tornou-se uma espécie de concurso relacionado a uma rotina de informações variáveis e sem nexo com os objetivos da cooperação mútua utilitária, e, mesmo assim, a maior parte dos usuários entende ser indispensável o registro do cotidiano.

O Youtube ${ }^{26}$, por exemplo, consagrou-se por conceber um canal de exibição de vídeos gratuitos onde pessoas postam seus vídeos e compartilham com demais usuários, difundindo, com alta velocidade, o fato, a notícia ou qualquer evento em que ele está participando com seus amigos. A sociedade digital está sendo representada por usuários que cultivam e massageiam seus próprios egos.

Os braggers também exibem sua vida nesse espaço virtual. Basta registrar um vídeo de seu cotidiano e postar na rede. O Youtube é considerado um site de cultura participativa, termo geralmente usado para descrever a aparente ligação entre tecnologias digitais mais acessíveis, conteúdo gerado por usuários e algum tipo de alteração nas relações de poder entre os segmentos de mercado da mídia e seus consumidores. ${ }^{27}$

Pessoas gravam programas feitos em suas casas, em pequenas e singelas acomodações e jogam as imagens no Youtube. Os bloggers (usuários de rede que criavam textos com opiniões escritas) agora estão em vídeos, utilizando-se da voz para enviar mensagens, dar opiniões ou recados (chamados de vloggers ${ }^{28}$ ).

O que chama atenção no estudo da linguagem e da comunicação social é que segundo pesquisas feitas pelos diretores de comunicação midiática, o Youtube Broadcast yourself ("Transmita-se"), que contém vídeos mais populares tendem a pender em proporção e visualização mais em favor dos vídeos criados por usuários do que por empresas especialistas em comunicação em massa. ${ }^{29}$

Nessa forte tendência de participação de vídeos caseiros que substituem os vídeos profissionais - cultura participativa dos amadores - bem como contemplação do ser enquanto

\footnotetext{
25 Revista Época. Disponível em http://epoca.globo.com/vida/noticia/2014/02/quem-aguenta-tantobexibicionismo-nas-redes-sociaisb.html. Acesso em 29 / março/ 2016.

26 BURGESS, Jean. Youtube e a Revolução digital: como o maior fenômeno da cultura participativa transformou a mídia e a sociedade. Tradução Ricardo Giassetti. São Paulo: Aleph, 2009, p. 28.

${ }^{27}$ Ibidem.

${ }^{28}$ Vlog é a abreviação de vídeo + blog. O vlogger é a pessoa que cria um tipo de blog - considerada uma página na internet - mas que usa os vídeos como conteúdos dominantes.

${ }_{29}$ Pouco mais da metade do material, ou 2.177 vídeos, foi codificada como originária de fontes criadas por usuários - conteúdo produzido fora da mídia de massa, da radiofusão ou da mídia dominante. A maioria desses vídeos é constituída por vlogs (quase 40\%), o formato coloquial tão emblemático do conteúdo criado por usuários do Youtube. BURGESS, Jean. Op. cit. p, 67.
} 
celebridade, encontra-se uma imperatividade de ações voltadas ao ser humano como produtor e consumidor das próprias informações, enfraquecendo, sobremaneira, os intermediários que sobrevivem desse tipo de serviço de comunicação e informação midiática.

\section{A cultura do ódio: haters que se acham formadores de opinião}

Sob o aspecto da psique, o self é um elemento da personalidade humana. Pode-se dizer, ainda, que ela é considerada propriedade da personalidade humana, pois representa o eu. No campo jurídico, ele está intimamente ligado ao direito personalíssimo. Quando se fala em pessoa, a imagem, a honra, a intimidade são substantivos que designam valores fundamentais para o ser humano. Esses substantivos estão incorporados ao self.

Para Winnicott, o self seria o produto de processos dinâmicos que asseguram a unidade e a totalidade do sujeito. Winnicott não trata o self como ego, mas sim a pessoa que é "eu", que possui uma totalidade baseada no funcionamento do processo de maturação. O ser humano, para Winnicott, "nasce como um conjunto desorganizado de pulsões, instintos, capacidades perceptivas e motoras" que conforme progride o desenvolvimento vão se integrando, até alcançar uma imagem unificada de si e do mundo externo. ${ }^{30}$

A ira e o amor, a felicidade e a tristeza, por exemplo, estão intimamente atrelados com sentimentos que afloram dos seres humanos e que são inerentes ao estado psíquico de cada um.

Os usuários da Internet que, de alguma forma, não concordam com pensamentos ou mensagens inseridas no universo digital, ou que não toleram imagens, personalidades, frases e diversidades culturais, podem se transformar em pessoas que lançam mão de seu tempo para hostilizar os outros usuários na rede, criando, de uma forma célere e bem ardilosa, meios de agredir os outros, maculando a honra e imagem dos demais usuários. São chamados haters.

Os haters são pessoas que odeiam outras pessoas usuárias da Internet ou de redes sociais ${ }^{31}$. No mundo virtual, é considerado hater aquele que não tem o que fazer e passa todo o tempo disponível realizando ataques gratuitos a outros usuários que possuem opinião diferente. Por ter em sua essência a intolerância, ele passa a cultivar o ódio nas redes.

Segundo pesquisa, as mensagens violentas ganharam espaço na internet no Brasil, aumentando, nos últimos três anos, cerca de $203 \%$ o número de páginas denunciadas à ONG

\footnotetext{
${ }^{30}$ BLEICHMAR, N. M. e BLEICHMAR, C.L. A Psicanálise depois de Freud: teoria e clínica. Porto Alegre: Artes Médicas, 1992, pp. 34-35.

${ }^{31}$ Disponível em http://www.tecmundo.com.br/erro-404/6071-erro-404-o-submundo-dos-haters.htm. Acesso em 29/ março/ 2016.
} 
Safernet, por divulgar "conteúdos de intolerância racional, religiosa, neonazistas, xenofobia e homofobia. ${ }^{32}$

A preocupação é tanta que Organizações Não Governamentais (ONGs) e outros órgãos de repressão estão colocando pessoas especializadas em computação e telemática como usuários em redes sociais para descobrirem a autoria desses tipos de crimes.

Essa cultura ao ódio acaba sendo alarmante à medida que a Internet é a extensão do pensar, do sentir e do agir do ser humano. A Internet representa a imagem da sociedade refletida nos monitores. A identificação ideológica de um ser com o outro com convergência para se curvar e participar da cultura do ódio traz um resultado que incita cada vez mais a violência e arregimenta mais seguidores que também concordam com o posicionamento favorável à intolerância.

A questão é que a repercussão imediata do bem e do mal na Internet tem o grau de velocidade acelerado e estimula a criação de canais fechados de comunicações, criando, cada vez mais, grupos criminosos.

Existem pessoas que utilizam redes sociais como forma de "ciberintimidação" de outras pessoas. Cresce o "uso de tecnologias digitais para intimidar pessoas, especialmente por meio da publicação de vídeos humilhantes ou ofensivos ou do uso de vídeos para documentar e enaltecer atos de violência." 33

Desse conflito de interesses, surge o dano moral, que é "a privação ou diminuição daqueles bens que têm um valor precípuo na vida do homem". Esses bens representam "a paz, a tranquilidade de espírito, a liberdade individual, a integridade individual, a integridade física, a honra e os demais sagrados afetos". ${ }^{34}$

Os discursos da mídia sobre as "questões de moralidade no Youtube" e a "criação da nova categoria de 'ciberintimidação' podem ser vistos como sintomas do desconforto e incerteza que cercam o campo de atuação da mídia e a autoridade moral”, que se verificam incontroladas "pelo uso em massa das novas tecnologias de mídia para a publicação autônoma, como as câmeras de telefones celular e a internet". ${ }^{35}$

O grande poder de transformação da Internet traz interações praticamente instantâneas ocorridas a todo o momento, influindo de forma positiva ou negativa no pensar humano. Essa integração entre pessoas que se voltam a propagar o mal no universo digital

\footnotetext{
${ }^{32}$ Há apologia e incitação de crimes contra a vida, e a maior parte da intolerância foi no Facebook.

Disponível em http://www.jogodopoder.com/blog/politica/debate-disseminacao-do-odio-e-a-intolerancia-nainternet/. Acesso em 30 de março de 2016.

${ }^{33}$ BURGESS, Jean. Op. cit. pp 40-41.

${ }^{34}$ CAHALI, Yussef Said. Dano Moral. 2. ed. São Paulo: Revista dos Tribunais, 1998, p. 28.

${ }^{35}$ Ibidem.
} 
causa preocupação aos usuários e ao Estado, porque os valores morais estão cada vez mais sendo pisoteados nas interlocuções humanas.

5. Valores morais na sociedade digital: reflexos da cibercultura ou declínio educacional?

No plano da banalidade do exibicionismo e da cultura do ódio, ambas intensificadas no mundo virtual, surge uma dúvida crucial: tais comportamentos são reflexos da cibercultura e, portanto, sujeitas a possíveis correções, e/ou são espelhos de uma sociedade sem conceitos formados, sem educação adequada, a ponto de não refletir sobre o certo ou errado?

A Lei 12.965/2014, que promulgou o Marco Civil da Internet, disciplina o uso rede digital e tem como fundamento o respeito à liberdade de expressão e os direitos humanos, o desenvolvimento da personalidade e o exercício da cidadania em meios digitais.

A mesma lei traz a concepção de que cabe aos usuários preservar os princípios da pluralidade e a diversidade, a livre concorrência e a defesa do consumidor, determinando uma postura de respeito mútuo dentro do ambiente virtual.

$\mathrm{O}$ art. $3^{\circ}$ da citada lei, traz ainda como princípios, a responsabilização dos agentes de acordo com suas atividades, nos termos da lei, a preservação da natureza participativa da rede e a liberdade dos modelos de negócios promovidos na internet. Trouxe, ademais, a lei, o direito de acesso à Internet como forma de inclusão digital, a fim de possibilitar a todos o acesso a informações e participação na vida cultural e na condução dos assuntos públicos.

Para que o exercício pleno da acessibilidade virtual possa fluir de forma harmônica, deve o usuário respeitar os direitos personalíssimos de todos os usuários, evitando, de todo modo, causar danos a terceiros no ambiente digital.

A banalização do exibicionismo e a construção de uma cultura ao ódio violam, sobremaneira, os princípios que regem o Marco Civil da Internet, pois deve ser preservada pluralidade e a diversidade dos usuários, sobretudo no que diz respeito à serenidade e razoabilidade do conteúdo das publicações e inserções de imagens em redes sociais.

Caso não ocorra o respeito a esses princípios, pode ocorrer a ineficácia concreta da exequibilidade da lei. Edgar Morin adverte que "o progresso também depende da consciência humana." Para tanto, o "progresso adquirido deve se regenerar incessantemente." 36

Ao se penetrar nos diálogos mantidos por usuários exibicionistas e nas hostilizações feitas pelos haters, a exposição de manifestações contrárias aos princípios do Marco Civil

\footnotetext{
${ }^{36}$ MORIN, Edgar. Op. cit., p. 45.
} 
acaba afetando sensível parte do patrimônio moral dos usuários, como honra e reputação. $\mathrm{O}$ dano molesta a parte afetiva da moral, como dor, tristeza, e, também pode causar outros danos extrapatrimoniais dependendo do tipo de comentário ou manifesto feito em rede. ${ }^{37}$

Os direitos e garantias previstos na Constituição Federal, em seu artigo $5^{\circ}$, resguardam também proteção ao desenvolvimento da pessoa. Analisando-se sob a ótica do princípio fundamental da dignidade da pessoa humana (artigo $1^{\circ}$, da Carta Federal), vislumbra-se a pessoa como o bem supremo e valor insuperável, razão da criação e existência do Estado. Não se pode conceber a inversão desses valores. ${ }^{38}$

Os valores morais, tido como reguladores de uma sociedade, devem ser respeitados por seus usuários, sob pena de supressão do patrimônio social impingido pela lei. Vasquez, ao expressar seu entendimento sobre a moral, ensina que se trata de um

\footnotetext{
“(...) sistema de normas, princípios e valores, segundo o qual são regulamentadas as relações mútuas entre os indivíduos ou entre estes e a comunidade, de tal maneira que estas normas, dotadas de um caráter histórico e social, sejam acatadas livres e conscientemente, por uma convicção íntima, e não de uma maneira mecânica, externa ou impessoal". 39
}

Como o universo digital compreende a inclusão de diversos diálogos mantidos por seus usuários, os valores morais devem ser preservados pelos remetentes e destinatários das discussões mantidas nesse campo virtual, porque a moral é a base que sustenta a engrenagem normativa, ressaltando os princípios e os valores da comunidade, cujo respeito deve ser mantido e observado mutuamente pelos indivíduos que nela navegam diuturnamente.

O hábito de se praticar o bem e estabelecer um debate harmônico entre os usuários são de significativa importância aos internautas. Isso porque o hábito que cultua o exibicionismo extremo e, de outro lado, a expansão de uma cultura de intolerância podem levar o mundo digital ao caos, desvirtuando toda finalidade pela qual ele foi criado.

Aristóteles adverte que nenhuma das virtudes morais surge nos homens "por natureza" porque o que é "por natureza não pode ser alterado pelo hábito". A "natureza nos dá a capacidade de recebê-las (as virtudes), e tal capacidade se aperfeiçoa com o hábito". 40

\footnotetext{
${ }^{37}$ CAHALI, Yussef Said. Op. cit. pp. 28-29.

38 DELGADO, Mário Luiz; ALVES, Jones Figueirêdo (Org.). Questões Controvertidas: Séries Grandes temas de Direito Privado. São Paulo: Editora Método, 2004. p. 451.

MONTEIRO FILHO, Raphael de Barros et al. Comentários ao Novo Código Civil: das pessoas: (Arts. $1^{\mathrm{a}}$ ao 78). Rio de Janeiro: Editora Forense, 2010. p. 132.

${ }^{39}$ VÁSQUEZ, Adolfo Sánchez. Ética. 18. ed. Rio de Janeiro: Civilização Brasileira, 1998, p. 36.

${ }^{40}$ ARISTÓTELES. Ética a Nicômaco. São Paulo: Martin Claret, 2012. p. 26
} 
Sobressai, portanto, do hábito, um rol de elementos capazes de reformular a conduta que se pode entender como lesiva à dignidade da pessoa humana. Se a cultura ao ódio se torna hábito, ela pode se revelar comum à medida que todos os demais usuários passarem a ofender reciprocamente uns aos outros.

Veja o exibicionismo, por exemplo: tornou-se rotineira a postagem da intimidade e privacidade das pessoas, pouco importando a utilidade ou efeitos que os compartilhamentos possam trazer para o usuário. Do mesmo modo, a cultura ao ódio, acoplado no prazer que expressa a discriminação de pessoas, também pode virar um hábito de usuários que não possuem total dimensão das consequências negativas que tais condutas representam às vítimas e à própria segurança jurídica do sistema e ambiente digital.

Se para Aristóteles a virtude está no meio, quer dizer que tanto a carência de informações quanto os excessos de condutas danosas podem significar o rompimento da justamedida de todas as coisas. Cabe à virtude - conforme lição aristotélica - mediar as extremidades, tanto nas ações quanto nas paixões. ${ }^{41}$

A união sistemática de diversos seres racionais no ambiente virtual também está regrada por normas de conduta. Essas normas de conduta revelam a base dos valores morais que devem ser respeitadas pelas pessoas que ingressam em rede, concebida como tal, apenas uma expansão do real, daquilo que efetivamente se concretiza em suas vidas.

Kant ressalta que o homem é submetido a provocações externas e que, às vezes, deixa de pensar racionalmente por questões adversas a sua vontade. $\mathrm{O}$ homem, compreendido enquanto fenômeno, e daí deve ser analisada sua dimensão empírica, estaria submetido à uma determinação causal, mas, de outra parte, estaria também ele orientado por sua dimensão inteligível. Tanta uma quanta outra dimensão possui em comum a "liberdade". E desse "reconhecimento da possibilidade ontológica da liberdade, como ideia transcendental, não deriva porém logo a possibilidade de conhecimento da culpa moral do atuar". ${ }^{42}$

Os seres racionais estão sujeitos à lei, “em virtude da qual cada um deles nunca deve tratar-se a si e aos outros como puros meios, mas sempre e simultaneamente como fins em si." Daí brota uma união sistemática de seres racionais por meio de leis objetivas comuns, ou seja, "um reino o qual atendendo a que tais leis têm precisamente por escopo a relação mútua de todos estes seres". 43

\footnotetext{
${ }^{41}$ Ibid, p. 30.

${ }^{42}$ KANT, Immanuel. Fundamentação da Metafísica dos Costumes. Trad. Antônio Pinto de Carvalho. Companhia Editoria Nacional, p. 122.

${ }^{43}$ Ibid, p. 31.
} 
Nesse ponto, os valores morais no ciberespaço podem estar reprimidos tanto por uma cibercultura na qual os participantes somente atuam como reprodutores de pensamentos, mensagens ou ações paritárias, quanto pela própria ausência de educação moral e cívica.

O exibicionismo, por exemplo, destila a autopromoção, como protagonismo de uma vida repleta de ações, eventos e de entretenimentos que são divulgados para ostentar uma pseuda felicidade dos braggers. O compartilhamento do ódio e da intolerância cria novas tribos que querem expressar seu poder de intimidação perante os demais usuários, inferiorizando pessoas por questões relacionadas à raça, etnia, gênero, religião, orientação sexual, além de outros aspectos.

A Internet, contudo, não pode ser entendida como um canal democrático de expressão a ponto de se tornar uma anarquia, pois, assim se tornando e se mantendo, ficará em total descompasso com os valores morais da sociedade.

Deve-se, pois, repensar de que forma pode ser feita a reestruturação moral do sistema cibernético de tal modo a renovar a necessidade de se impor o cumprimento das normas e princípios pregados pela norma. Não há como deixar os valores morais à deriva quando ocorrer a troca de informações nos canais digitais, pois, caso haja tal negligência, estar-se-ia permitindo a supressão das diretrizes e princípios evocados pelo Marco Civil da Internet.

\section{CONCLUSÃO}

A informação criada e postada a cada segunda na Internet pode ser mensurada desde uma simples mensagem ou imagem exibicionista de uma pessoa para compartilhamento com usuários da rede, até um profundo artigo científico focado em pesquisa que vise o aperfeiçoamento do conhecimento sobre alguma matéria.

A intimidade é um bem valioso para todo ser humano. Porém, diante da difusão da autopublicidade e o desejo de ser contemplado perante um grupo de pessoas, a ansiedade das postagens e dos compartilhamentos são feitos de modo inútil e banal.

O excesso de exibicionismo dos internautas revela uma rotina diária incorporada no mundo dos usuários das redes sociais. Essa prática instantânea demonstra que os valores morais da sociedade informacional estão enfraquecidos pelo hábito de compartilhamento de uma linguagem que demonstra o declínio do ser humano em relação ao respeito à dignidade humana. 
Os haters e demais usuários que cultuam o ódio dentro da rede virtual está crescendo a cada dia, causando perplexidade para os demais usuários que se sentem vítimas de perseguições feitas por pessoa intolerantes que navegam no ciberespaço.

Os direitos humanos, notadamente os de personalidade, estão sendo lesados pelos próprios internautas quando não respeitam a pluralidade e a diversidade dos usuários, sobretudo no que diz respeito ao fundamento do desenvolvimento da personalidade na rede digital. $\mathrm{O}$ desenvolvimento da personalidade está intimamente ligado com o hábito e com a finalidade social da rede.

A efetividade da lei como resgate dos valores morais devem ser fomentados e executados pelo Estado, sob pena de se conceber que o Marco Civil trouxe em seu bojo verdadeiras letras mortas, criando e alimentando atos e linguagem criminosas, capazes de cultivar o mal ou manter a inutilidade de um espaço precioso, pela simples justificativa de que existe liberdade de expressão e que o universo digital é infinito.

A liberdade de expressão, de comunicação e manifestação de pensamento, consagrados pela Carta Magna, esbarra no dever de ponderação e de razoabilidade da publicidade de eventos, sobretudo quando resultar no desvirtuamento da finalidade da linguagem como utilidade e propagadora de conhecimento.

A escassez da moralidade virtual é amplificada pela divulgação da ideia de que no mundo virtual dificilmente o usuário é visto como criminoso, sendo difícil a interceptação de conversas por meio de mensagens de texto. Essa pulverização dos constrangimentos ilegais que ocorrem diariamente na rede é transformada em processos judiciais e a democratização da produção cultural acaba invertendo os julgamentos de valores que são preconcebidos e comandados por usuários que se acham investidos num certo poder de comando.

Repensar sobre a manifestação participativa, solidária e direcionada ao bem comum é medida indispensável para reestruturação do sistema virtual.

Não se pode, portanto, deixar que usuários deturpadores do sistema informacional coloquem à deriva as diretrizes e princípios evocados pelo Marco Civil, criando e alimentando atos e linguagens criminosas, capazes de cultivar o mal ou manter a inutilidade de um espaço precioso pela simples justificativa de que o direito a liberdade de expressão é inexpugnável e que o universo digital é infinito e incontrolável. 


\section{REFERÊNCIAS}

ARISTÓTELES. Ética a Nicômaco. São Paulo: Martin Claret, 2012.

BAUMAN, Zygmunt. Vida para consumo: a transformação das pessoas em mercadoria. Rio de Janeiro. Zahar, 2008.

BLEICHMAR, N. M. e BLEICHMAR, C.L. A Psicanálise depois de Freud: teoria e clínica. Porto Alegre: Artes Médicas, 1992.

BRASIL. Constituição da República Federativa do Brasil. Senado, 1988. Disponível em http://www.planalto.gov.br/ccivil_03/Constituicao/Constituicao.htm. Acesso 29/março/2016.

BRASIL. Lei 12.965, de 23 de abril de 2014. Marco Civil da Internet. Disponível em http://www.planalto.gov.br/ccivil_03/_ato2011-2014/2014/lei/112965.htm. Acesso 29/ março/2016.

BURGESS, Jean. Youtube e a Revolução digital: como o maior fenômeno da cultura participativa transformou a mídia e a sociedade. Tradução Ricardo Giassetti. São Paulo: Aleph, 2009.

BUSCATO, Marcela. CARRERA, Isabela. Revista Época. Disponível em http://epoca.globo.com/vida/noticia/2014/02/quem-aguenta-tanto-bexibicionismo-nas-redessociaisb.html.

CAHALI, Yussef Said. Dano Moral. 2. ed. São Paulo: Revista dos Tribunais, 1998.

CASTELLS, Manuel. A sociedade em rede. A Era da Informação: economia, sociedade e cultura. Volume I, 5 ed., São Paulo: Paz e Terra, 2001.

CEBRIÁN, Juan Luis. A rede. Tradução Lauro Machado Coelho. São Paulo: Summus, 1999.

CICCO, Cláudio de. História do pensamento jurídico e da filosofia do direito. 3 ed. São Paulo: Saraiva, 2006.

CUNHA, Antonio Geraldo da. Dicionário etimológico da língua portuguesa. 4 ed., Rio de Janeiro: Lexikon, 2010.

DELGADO, Mário Luiz; ALVES, Jones Figueirêdo (Org.). Questões Controvertidas: Séries Grandes temas de Direito Privado. São Paulo: Editora Método, 2004.

DICIONÁRIO MICHAELIS on line. Disponível em http://michaelis.uol.com.br/moderno/ingles/index.php?lingua=inglesportugues\&palavra=brag,

FREUD, S. Introdução ao narcisismo. in Obras Completas. Buenos Aires: Amorrortu Editores, vol. 14.

FRIEDMAN, THOMAS L. O mundo é plano. Rio de Janeiro: Ed. Objetiva, 2007. 
GIANNETTI, Eduardo. Felicidade: diálogos sobre o bem-estar na civilização. São Paulo: Companhia das Letras, 2002.

HAMANN, Rennan. Tecmundo: Erro 404: o submundo dos haters. Disponível em http://www.tecmundo.com.br/erro-404/6071-erro-404-o-submundo-dos-haters.htm.

HEGEL, Georg Wilhelm Friedrich. Princípios da filosofia do direito. Tradução: Orlando Vitorino. São Paulo: Martins Fontes, 2009.

HUME, David. Tratado da natureza humana: uma tentativa de introduzir o método experimental de raciocínio nos assuntos morais.

KANT, Immanuel. Fundamentação da Metafísica dos Costumes. Trad: Antônio Pinto de Carvalho. Companhia Editoria Nacional.

LÉVY, Pierre. O que é virtual? Tradução Paulo Neves. São Paulo: Ed. 34, 2009.

, Pierre. Cibercultura. Tradução Carlos Irineu da Costa. São Paulo: Editora 34, 2009.

MATOS, Karla Cristina da Costa e Silva. O valor econômico da informação nas relações de consumo. São Paulo: Almedina.

MONTEIRO FILHO, Raphael de Barros et al. Comentários ao Novo Código Civil: das pessoas: (Arts. $1^{\text {a }}$ ao 78). Rio de Janeiro: Editora Forense, 2010.

MORIN, Edgar. Rumo ao abismo? Ensaio sobre o destino da humanidade. Trad. Edgard de Assis Carvalho, Mariza Perassi Bosco. Rio de Janeiro: Bertrand Brasil, 2011.

NOVALIS, F. von Hardenberg. Pólen. Trad. Rubens Rodrigues Torres Filho, São Paulo, 1988.

O GLOBO: Jogo do poder. Debate: disseminação do ódio e a intelorância na internet. Disponível em http://www.jogodopoder.com/blog/politica/debate-disseminacao-do-odio-e-aintolerancia-na-internet/

OLIVER, Richard W. Como serão as coisas no futuro. Tradução Nathalie Fragoso. São Paulo. Negócio Editora, 1999.

RICOUER, Paul. Parcous de la reconnaissance. Paris: Gallimar, 2003.

SAUSSURE, Ferdinand de. Curso de Linguísta Geral. Org. Charles Bally e Albert Sechebaye. Trad. Antonio Chelini. São Paulo, Cultrix, 2006.

VÁSQUEZ, Adolfo Sánchez. Ética. 18. ed. Rio de Janeiro: Civilização Brasileira, 1998. 